\title{
Attenuation of reserpine-induced fibromyalgia via ROS and serotonergic pathway modulation by fisetin, a plant flavonoid polyphenol
}

\author{
XIANLI YAO ${ }^{1}$, LI LI $^{2}$, AMIT D. KANDHARE ${ }^{3}$, \\ ANWESHA A. MUKHERJEE-KANDHARE ${ }^{3}$ and SUBHASH L. BODHANKAR ${ }^{3}$
}

${ }^{1}$ Department of Neurological Rehabilitation, Zhengzhou Central Hospital Affiliated to Zhengzhou University, Zhengzhou, Henan 450000; ${ }^{2}$ Encephalopathy Department, The Traditional Chinese Medicine Hospital of Zhangqiu District, Jinan, Shandong 250200, P.R. China; ${ }^{3}$ Department of Pharmacology, Poona College of Pharmacy, Bharati Vidyapeeth Deemed University, Pune-411038, Maharashtra, India

Received May 11, 2019; Accepted November 6, 2019

DOI: $10.3892 /$ etm.2019.8328

\begin{abstract}
Fibromyalgia (FM) is a chronic complex musculoskeletal disorder characterized by widespread musculoskeletal pain accompanied by fatigue, sleep disturbance, memory defects and mood changes. Fisetin, a plant flavonoid polyphenol, has been reported to possess potent antioxidant, antinociceptive and neuroprotective activities. The present study aimed to evaluate the efficacy of fisetin against reserpine-induced FM (RIF) in rats. RIF was induced in male Wistar rats (180-220 gm) using reserpine $(1 \mathrm{mg} / \mathrm{kg}$; subcutaneous; once daily for 3 consecutive days) and the rats were treated with fisetin $(5,10$ and $25 \mathrm{mg} / \mathrm{kg}$ ) for 21 days. Various behavioral, biochemical and molecular parameters were evaluated. Administration of reserpine induced allodynia, hyperalgesia and depression, which were significantly ameliorated $(\mathrm{P}<0.05)$ by fisetin $(10$ and $25 \mathrm{mg} / \mathrm{kg})$, as reflected by an increase in paw and tail withdrawal latency, increased paw withdrawal threshold, and decreased immobility time. Reserpine led to decreased biogenic amine levels [5-hydroxytryptamine
\end{abstract}

Correspondence to: Dr Subhash L. Bodhankar, Department of Pharmacology, Poona College of Pharmacy, Bharati Vidyapeeth Deemed University, Paud Road, Erandwane, Pune-411038, Maharashtra, India

E-mail:drslbodh@gmail.com

Abbreviations: 5-HT, 5-hydroxytryptamine; CNS, central nervous system; DA, dopamine; DMSO, dimethyl sulfoxide; DOPAC, 3,4-dihydroxyphenylacetic acid; FM, fibromyalgia; FST, forced swimming test; GSH, glutathione; H2DCFDA, dichlorodihydrofluorescein diacetate; MDA, malondialdehyde; NA, noradrenaline; NE, norepinephrine; NO, nitric oxide; RIF, reserpine-induced fibromyalgia; ROS, reactive oxygen species; SC, Schwann cell; SOD, superoxide dismutase; TST, tail suspension test

Key words: 5-HT, dopamine, FM, fisetin, immunohistochemistry, NA, ROS, reserpine
(5-HT), noradrenaline (NA) and dopamine (DA)] and increased the ratio to their metabolite 3,4-dihydroxyphenylacetic acid. 5 -hydroxyindoleacetic acid in the spinal cord, thalamus and prefrontal cortex was significantly decreased $(\mathrm{P}<0.05)$ by fisetin. Immunohistological analysis of brain tissue revealed that fisetin significantly inhibited $(\mathrm{P}<0.05)$ reserpine-induced depletion of 5-HT. It also significantly inhibited $(\mathrm{P}<0.05)$ elevated oxido-nitrosative stress and reactive oxygen species (ROS) levels, as analyzed by flow cytometry in RIF rats. Fisetin exerts its antinociceptive and anti-depressive potential via modulation of decreased levels of biogenic amines (5-HT, NA and DA), elevated oxido-nitrosative stress and ROS to ameliorate allodynia, hyperalgesia, and depression in experimental RIF.

\section{Introduction}

Fibromyalgia (FM) is a chronic musculoskeletal syndrome, mainly characterized by widespread musculoskeletal pain accompanied by fatigue, neuropathic pain, memory and neurocognitive impairment, chronic fatigue syndrome, joint stiffness, sleep disturbance, emotional distress, restless leg syndrome, depression, mood disorders and dysmenorrhoea (1). It has been documented that dysregulation of pain pathways triggers central sensitization, which increases the sensitivity to pain during FM (2). Thus, allodynia, hyperalgesia and impulsive pain are the clinicopathological features of neuropathic pain due to FM (2). A study estimated that 3-6\% of the world population is -affected by FM and that it causes substantial morbidity and disability, predominantly in women (3). Previous studies have suggested that FM significantly affects daily living activities and the health of patients, worsening their quality of life and leading to a loss of productivity $(2,4,5)$. The estimated cost of treatment for FM is between \$12-14 billion per year, whereas the mean annual cost per patient is $\$ 2,274-9,573$, worldwide (6). Thus, FM imposes a significant economic burden on healthcare systems.

Although the exact molecular mechanism responsible for the induction of FM remains to be elucidated, an imbalance 
in biogenic amines [including 5-hydroxytryptamine (5-HT), norepinephrine (NE) or noradrenaline (NA), and dopamine (DA)] is thought to play an important role in the pathogenesis of central nervous system (CNS) pain during FM $(7,8)$. Clinically, it has been shown that FM is associated with decreased levels of these biogenic amines in the cerebrospinal fluid of patients (9). A previous study noted that DA plays a vital role in pain control (7) whereas, two inhibitory neurotransmitters, NE and 5-HT, are important for the response to harmful stimulation (10). Oxidation of DA and NE in the cytosol causes cellular damage (11). Therefore, various efforts have been taken to ameliorate the pain symptoms in FM via an increase in the activity of neurotransmitters (7). Previous studies have also reported that elevated oxidative stress and an altered antioxidant status are responsible for the induction of FM $(12,13)$. Patients with FM exhibit elevated levels of reactive oxygen species (ROS) in mononuclear cells, suggesting the crucial role of oxidative stress in FM (14). Studies have also reported that alterations in the hypothalamic-pituitary-adrenal axis, central sensitization, muscular dysfunction and alterations in endogenous pain-modulating systems are several other underlying mechanisms of FM $(7,8)$.

The current treatment strategy for FM, which includes non-steroidal anti-inflammatory drugs (such as ibuprofen, diclofenac and naproxen), selective serotonin re-uptake inhibitors (including dapoxetine, fluoxetine and paroxetine) and opiate antagonists (naltrexone), mainly focuses on symptomatic relief of pain and depression (15-17). However, these treatment regimens involve various unwanted side effects, including serotonin syndrome, the risk of seizures, anxiety, drowsiness and loss of appetite (18). Progress has been made in the development of non-pharmacological therapies for FM, which include cognitive behavioral therapy, acupuncture and aerobic exercise (19). However, these non-pharmacological interventions provide relief in only a fraction of patients, which limits their clinical application. Thus, there is a need for the development of a new therapeutic entity with a multidisciplinary approach for more effective and specific management of FM. The antinociceptive efficacy of antioxidant compounds has been reported clinically (20). Recently, a potent antioxidant, $\alpha$-lipoic acid, has been proposed for the management of musculoskeletal pain associated with FM (21). A number of animal models that mimic FM have been employed for the development of new therapeutic moieties for the management of FM (22). Reserpine, a rauwolfia indole alkaloid, has been widely used as an antihypertensive agent, but its chronic administration is associated with major depression and musculoskeletal pain (22). Thus, reserpine-induced FM (RIF) is a well-established and widely used animal model that mimics the etiological and clinical features of FM, including decreased levels of biogenic amines, depression-like syndrome and the induction of musculoskeletal pain reflected by an increased paw or tail withdrawal threshold (22).

Flavonoids are polyphenolic compounds which are widely known for their antioxidant, anti-inflammatory and antinociceptive potential (23). Fisetin (7,3',4'-flavon-3-ol) is an important dietary plant polyphenol flavonoid that possesses a broad range of pharmacological properties including anti-inflammatory, antioxidant, anticarcinogenic, neuroprotective, cardioprotective, antiulcer and antiallergic effects $(24,25)$. A previous study demonstrated that the administration of fisetin modulated the levels of 5-HT, DA, epinephrine and NE in the brain via the inhibition of monoamine oxidase activity in astrocyte cells (26). Fisetin exhibits potential against an array of neurological diseases including epilepsy, Huntington's disease, Parkinson's disease and Alzheimer's disease (25,27-33). Zhen et al (34) reported that fisetin ameliorates allodynia and hyperalgesia by inhibiting the release of NT in the dorsal root ganglion, spinal cord and sciatic nerve of experimental animals. Another study reported that reserpine-induced depressant-like effect was significantly ameliorated by fisetin via inhibition of the depletion of brain monoamines (34). However, to the best of our knowledge, the effect of fisetin on RIF is yet to be elucidated. Hence, the present study was designed to evaluate the potential of fisetin against the modulation of various behavioral, biochemical and molecular alterations induced by reserpine in an experimental FM-like murine model.

\section{Materials and methods}

Animals. A total of 72 adult male Wistar rats (weight, 180-200 g; age, 8-10 weeks) were obtained from the National Institute of Biosciences (Pune, India). The animals were housed in groups of 7 inside solid-bottomed polypropylene cages $(435 \times 290 \times 150 \mathrm{~mm})$. They were maintained at $24 \pm 1^{\circ} \mathrm{C}$, with a relative humidity of $45-55 \%$ and 12 -h light/dark cycle. The acclimation period for the animals was two weeks, and they were maintained under pathogen-free conditions. The animals had free access to standard pellet chow (Nav Maharashtra Chakan Oil Mills, Ltd.) and water throughout the duration of the experiments. All experiments were carried out between 09:00 a.m. and 5:00 p.m. The experimental protocols were approved by the Institutional Animal Ethics Committee of Poona College of Pharmacy (Pune, India) and performed in accordance with the guidelines of the Committee for Control and Supervision of Experimentation on Animals, Government of India, on animal experimentation (35).

Drugs and chemicals. Fisetin ( $\geq 98 \%)$, reserpine, 5-HT, DA, NE, 5-hydroxyindole-3-acetic acid (5-HIAA), 3,4-dihydroxyphenylacetic acid (DOPAC), fluorescein isothiocyanate-Annexin $\mathrm{V}$, and propidium iodide were purchased from Sigma-Aldrich; Merck KGaA. 1,1',3,3'-Tetraethoxypropane, crystalline beef liver catalase, reduced glutathione (GSH), 5,5'-dithiobis (2-nitrobenzoic acid) (DTNB) were purchased from S.D. Fine Chemicals, Ltd. The serotonin receptor C (SR-2C) (D-12; cat. no. sc-17797) rabbit polyclonal antibody was purchased from Santa Cruz Biotechnology, Inc.

Habituation. During the first 5 days of the procedure, the animals were habituated to researcher handling, as well as to the different maneuvers, in order to reduce any discomfort caused by the experiments. The purpose of the habituation process was to minimize the bias that a stress response could introduce into the results.

$R I F$. FM was induced in rats according to a previously reported method $(22,36)$. After the habituation process, reserpine $(1 \mathrm{mg} / \mathrm{kg}$, once daily) was administered by subcutaneous (s.c.) injection over the flank and repeated for 3 consecutive days, 
with varied sites of injection at the flank. Reserpine was diluted in glacial acetic acid to a final concentration of $0.5 \%$ acetic acid in distilled water (vehicle). Animals from the normal group received the same volume of vehicle, but they were not administered reserpine. Then animals were divided randomly into 6 groups with 12 rats/group as follows. i) Normal group: The rats received distilled water $(1 \mathrm{mg} / \mathrm{kg}$, s.c.) for 3 consecutive days, but they were not administered reserpine. They were treated with $1 \%$ DMSO solution for the next 21 days. ii) Vehicle control group: The rats received reserpine $(1 \mathrm{mg} / \mathrm{kg}$, s.c.) for 3 consecutive days. They were treated with $1 \%$ DMSO solution for the next 21 days. iii) Fisetin $(5 \mathrm{mg} / \mathrm{kg})$-treated group $[\mathrm{F}(5)]$ : The rats received reserpine $(1 \mathrm{mg} / \mathrm{kg}$, s.c.) for 3 consecutive days. They were treated with fisetin $(5 \mathrm{mg} / \mathrm{kg})$ for the next 21 days. iv) Fisetin $(10 \mathrm{mg} / \mathrm{kg})$-treated group [F(10)]: The rats received reserpine $(1 \mathrm{mg} / \mathrm{kg}$, s.c.) for 3 consecutive days. They were treated with fisetin $(10 \mathrm{mg} / \mathrm{kg})$ for the next 21 days. v) Fisetin $(25 \mathrm{mg} / \mathrm{kg})$-treated group [F(25)]: The rats received reserpine $(1 \mathrm{mg} / \mathrm{kg}$, s.c.) for 3 consecutive days. They were treated with fisetin $(25 \mathrm{mg} / \mathrm{kg})$ for the next 21 days. vi) Pregabalin $(30 \mathrm{mg} / \mathrm{kg})$-treated group $[\mathrm{P}(30)]$ : The rats received reserpine ( $1 \mathrm{mg} / \mathrm{kg}$, s.c.) for 3 consecutive days. They were treated with pregabalin $(30 \mathrm{mg} / \mathrm{kg})$ for the next 21 days.

Fisetin was dissolved in $1 \%$ DMSO. The different doses of fisetin, namely 5,10 and $25 \mathrm{mg} / \mathrm{kg}$, and the dose of pregabalin (30 mg/kg) were selected based on previous studies $(29,36)$.

All the behavioral assays were performed by an observer blinded to the drug administration on days $0,7,14$ and 21 in the morning, and doses were administered immediately afterwards (37-39). An observer blinded to the drug administration performed the open field test and motor incoordination test (rotarod test) on day 21. At the end of the study (the 21st day) the rats were sacrificed under ether anesthesia, the brain was collected, and kept in liquid nitrogen $\left(-196^{\circ} \mathrm{C}\right)$ until analyzed.

\section{Behavioral tests}

Randall-Selitto paw pressure test. Mechanical nociceptive threshold, an index of mechano-hyperalgesia, was assessed according to a previously described method $(38,39)$. The nociceptive flexion reflex was quantified using the Randall-Selitto paw pressure device (UGO Basile Biological Research Apparatus, SRL). Nociceptive threshold was expressed in grams, as measured by applying increasing pressure to the left hind paw. Withdrawal of the hind paw was used to assess the nociceptive threshold.

Hargreaves test. The Hargreaves test was specifically designed to assess thermal pain sensation in rodents and it was performed according to a method described previously $(38,39)$ using standard apparatus (UGO Basile Biological Research Apparatus, SRL). The test consisted of placing the rat in a transparent acrylic box, with a mobile infrared heat lamp positioned underneath the targeted hind paw. A thermal radiant stimulus was then applied to the plantar surface, and the latency of the paw withdrawal response was measured automatically with the help of a photoelectric-sensitive device. The latency of the withdrawal response (the reaction time of each hind paw) was determined.

Von Frey hair test. Rats were placed individually on an elevated mesh $\left(1 \mathrm{~cm}^{2}\right.$ perforation) in a clear plastic cage and adapted to the testing environment for at least $15 \mathrm{~min}$. Von Frey hairs (IITC Life Science, Inc.) with calibrated bending forces (in grams) of different intensities were used to deliver punctuated mechanical stimuli of varying intensity. Starting with the lowest filament force, von Frey hairs were applied from below the mesh floor to the plantar surface of the hind-paw, with sufficient force to cause slight bending against the paw, and held for $1 \sec (38,39)$. Each stimulation was applied five times, with an inter-stimulus interval of 4-5 sec. Care was taken to stimulate random locations on the plantar surface. A positive response was noted if the paw was forcefully and immediately withdrawn. Paw withdrawal threshold was defined as the minimum pressure required to elicit a withdrawal reflex in the paw, at least once in the five trials. Voluntary movement associated with locomotion was not considered as a withdrawal response. Mechanical allodynia was defined as a significant decrease in withdrawal thresholds associated with von Frey hair application.

Tail immersion or flick test. Spinal thermal sensitivity was assessed via the tail immersion test according to a method described elsewhere $(38,39)$. Briefly, the terminal part of the tail $(1 \mathrm{~cm})$ of the rat was immersed in a water bath maintained at $55^{\circ} \mathrm{C}$ until tail withdrawal or signs of struggle were observed (the cut-off time was $15 \mathrm{sec}$ ). The duration of the tail withdrawal reflex was recorded.

Forced swim test (FST). The FST was performed according to a previously reported method $(38,39)$. The experiments were carried out using a polyvinyl chloride cylinder $(18.5 \mathrm{~cm}$ diameter, $25 \mathrm{~cm}$ height) filled with water to a height of $17 \mathrm{~cm}$. Water was maintained at $23 \pm 2^{\circ} \mathrm{C}$. Rats were placed into the water to quantify the immobility time, which was defined as an absence of all movement except motions required for keeping the head above the water. The time during which the rats remained immobile was recorded, in sec, during a period of $1 \mathrm{~min}$.

Tail suspension test (TST). The TST is based on the observation that a rat suspended by the tail shows alternate periods of agitation and immobility $(38,39)$. Animals were suspended $50 \mathrm{~cm}$ above the floor by means of adhesive tape, placed approximately $1 \mathrm{~cm}$ from the tip of the tail. The sum time of the immobility periods during was measured during a test period of $1 \mathrm{~min}$. Rats were considered immobile only when they hung passively and remained completely motionless.

Motor co-ordination test (Rota-Rod test). Motor coordination was evaluated by a Rota-Rod device, which was used according to a previously described method $(38,39)$. Rats were placed on the rotating rod of the Rota-Rod apparatus (Techno Electronics) for $1 \mathrm{~min}$. The time taken for the rat to fall from the rotating rod during the $1 \mathrm{~min}$ period=was recorded.

\section{Biochemical estimations}

Estimation of oxidative stress biomarkers in brain tissue. Thalamus samples $(50 \mathrm{mg})$ were rinsed with cold saline ( $0.9 \%$ sodium chloride), minced and homogenized at $1,077 \mathrm{x} \mathrm{g}$ $\left(4^{\circ} \mathrm{C}\right.$ for $\left.5 \mathrm{~min}\right)$ in chilled Tris buffer $(10 \mathrm{mM}, \mathrm{pH} 7.4)$ and diluted up to $5 \mathrm{ml}$. The homogenates were centrifuged at $10,000 \mathrm{x} \mathrm{g}$ at $0^{\circ} \mathrm{C}$ for $20 \mathrm{~min}$ and divided into aliquots to determine superoxide dismutase (SOD), GSH, malondialdehyde 
(MDA) and nitric oxide (NO) content according to previously described procedures (40-44).

Determination of SOD content. Briefly, $0.5 \mathrm{ml}$ tissue homogenate was diluted with $0.5 \mathrm{ml}$ of distilled water, to which $0.25 \mathrm{ml}$ ice-cold ethanol and $0.15 \mathrm{ml}$ ice-cold chloroform were added. This was mixed well using a cyclomixer and centrifuged at $748 \mathrm{x} \mathrm{g}$ at $4^{\circ} \mathrm{C}$ for $15 \mathrm{~min}$. To $0.5 \mathrm{ml}$ supernatant, $1.5 \mathrm{ml}$ carbonate buffer and $0.5 \mathrm{ml}$ EDTA solution were added. The reaction was initiated by the addition of $0.4 \mathrm{ml}$ epinephrine and the change in optical density/min was measured at $480 \mathrm{~nm}$ against a reagent blank. Epinephrine was added before assessing the optical density (OD). Change in OD (per min) at $50 \%$ inhibition to adrenochrome transition by the enzyme was taken as one enzyme unit. SOD activity was expressed as units/mg protein.

Determination of GSH content. Briefly, equal volumes of tissue homogenate (supernatant) and 20\% trichloroacetic acid (TCA) were mixed. The precipitated fraction was centrifuged at $748 \mathrm{x} \mathrm{g}$ at $4^{\circ} \mathrm{C}$ for $15 \mathrm{~min}$ and $2.0 \mathrm{ml}$ DTNB reagent was added to $0.25 \mathrm{ml}$ supernatant. The final volume was made up to $3.0 \mathrm{ml}$ with phosphate buffer. The developed color was read at $412 \mathrm{~nm}$ against a reagent blank. The amount of GSH was expressed as $\mu \mathrm{g} \mathrm{GSH} / \mathrm{mg}$ protein.

Determination of MDA content. Briefly, $2.0 \mathrm{ml}$ of the tissue homogenate (supernatant) was added to $2 \mathrm{ml}$ of freshly prepared $10 \% \mathrm{w} / \mathrm{v}$ TCA and the mixture was allowed to stand in an ice bath for $15 \mathrm{~min}$, the precipitate formed was separated by centrifugation at $748 \mathrm{x} \mathrm{g}$ at $4^{\circ} \mathrm{C}$ for $15 \mathrm{~min}$ and $2.0 \mathrm{ml}$ of clear supernatant solution was mixed with $2.0 \mathrm{ml}$ of freshly prepared TBA. The resulting solution was heated in a boiling water bath for $10 \mathrm{~min}$. It was then immediately cooled in an ice bath for $5 \mathrm{~min}$. The developed color was measured at $532 \mathrm{~nm}$ against a reagent blank. The results were expressed as $\mathrm{nM}$ of $\mathrm{MDA} / \mathrm{mg}$ protein.

Determination of nitrite level. The NO level was estimated as nitrite via the acidic Griess reaction after the reduction of nitrate to nitrite with vanadium trichloride. The Griess reaction relies on a simple colorimetric reaction between nitrite, sulfonamide and N-(1-naphthyl) ethylenediamine to produce a pink azo-product with a maximum absorbance at $543 \mathrm{~nm}$. The concentrations were determined using a standard curve of sodium nitrate and the results were expressed as $\mu \mathrm{g} / \mathrm{ml}$.

Estimation of the biogenic amine and metabolite content. The amount of DA, NE, 5-HT, DOPAC and 5-hydroxyindoleacetic acid in the spinal cord, thalamus and prefrontal cortex were measured using high-performance liquid chromatography, according to a previously reported method (45). The tissue samples were weighed and homogenized in an ultrasonic homogenizer with $0.2 \mathrm{M}$ perchloric acid and $0.1 \mathrm{mM}$ EDTA-2Na. After centrifugation $(15,000 \mathrm{x} \mathrm{g}$ for $15 \mathrm{~min}$ at $4^{\circ} \mathrm{C}$ ), the $\mathrm{pH}$ of the supernatant from each sample was adjusted to $\mathrm{pH} 3.5$ with sodium acetate. The adjusted supernatants were filtered and injected onto a reverse-phase column (SC-5ODS 3.0, $150 \mathrm{~mm}$; Eicom Co., Ltd.) with an ECD-300 electrochemical detector $(750 \mathrm{mV})$. The mobile phase consisted of $0.1 \mathrm{M}$ sodium acetate buffer, $0.1 \mathrm{M}$ citrate buffer, $5 \mathrm{mg} / \mathrm{l}$ EDTA-2Na, $190 \mathrm{mg} / \mathrm{l}$ sodium octane sulfonic acid and $17 \%$ methanol. The flow rate was maintained at $0.5 \mathrm{ml} / \mathrm{min}$. The amounts $(\mathrm{ng} / \mathrm{g}$ wet tissue weight) of DA, NE, 5-HT and their metabolites in each tissue were quantified by comparing sample peak areas with those of standards run on the same day $(n=4)$.

Preparation of single Schwann cell (SC) suspensions. Preparation of single SC suspensions and determination of apoptotic cell populations were performed as previously described (38). Briefly, brain samples were extensively perfused, in situ, in PBS to remove blood and then irrigated in a buffer containing HEPES $(10 \mathrm{mM}), \mathrm{KCl}(3 \mathrm{mM}), \mathrm{NaCl}(130 \mathrm{mM})$, $\mathrm{NaH}_{2} \mathrm{PO}_{4}, \mathrm{H}_{2} \mathrm{O}(1 \mathrm{mM})$ and glucose $(10 \mathrm{mM}, \mathrm{pH}$ 7.4). The brain thalamus tissue was homogenized and suspended in Hanks' balanced salt solution. The homogenate was then treated with trypsin for $10 \mathrm{~min}$ at $25^{\circ} \mathrm{C}$ and trypsin inhibitor for $5 \mathrm{~min}$ at $37^{\circ} \mathrm{C}$. The cell suspension was obtained by passing the trypsinized brain tissue through a nylon mesh. Cells were washed twice with cold PBS and then resuspended in $1 \mathrm{X}$ binding buffer at a concentration of $1-2 \times 10^{6}$ cells $/ \mathrm{ml}$.

ROS production in SC by dichlorodihydrofluorescein diacetate $\left(H_{2} D C F D A\right)$ probe using flow cytometry. ROS production was quantified using the $\mathrm{H}_{2}$ DCFDA dye method based on the ROS-dependent oxidation of DCFH-DA to DCF, according to a previously described method (46). An aliquot of $100 \mu \mathrm{l}$ thalamus cell suspension was transferred to a Falcon tube (Becton, Dickinson and Company) and incubated with $10 \mu \mathrm{l}$ of $10 \mathrm{mmol}$ $\mathrm{H}_{2}$ DCFDA for 15 min in the dark. The $\mathrm{H}_{2} \mathrm{O}_{2}, \mathrm{OH}^{-}$and ONOOproduced during the cellular oxidative response oxidized the nonfluorescent intracellular DCFH into highly fluorescent DCF. DCF fluorescence was assayed at $530 \mathrm{~nm}$ after excitation of cells at $488 \mathrm{~nm}$. Acquisition and analysis of the processed sample were performed on a flow cytometer using CellQuest software (version 5.1; Becton, Dickinson and Company).

Determination of 5-HT by immunohistochemistry in the rat brain thalamus. The flash-frozen brain was stored at $-80^{\circ} \mathrm{C}$ and immunohistochemistry for 5-HT protein was carried out as previously described (47). The SR-2C (D-12; cat. no. sc-17797) antibody (Santa Cruz Biotechnology, Inc.; 1:100; incubated for $45 \mathrm{~min}$ at room temperature) is a rat monoclonal antibody raised against amino acids 374-458 mapping at the $\mathrm{C}$-terminus of SR-2C of human origin, and it was counterstained with cresyl violet $(0.5 \%$ in sodium acetate; $\mathrm{pH} 3.5)$ for $5 \mathrm{~min}$. The 5-HT-positive neurons were identified by the presence of dense immunohistochemical staining within the thalamus under a light microscope. The images were analyzed using ImageJ (version 1.33; National Institutes of Health)

Statistical analysis. Data analysis was performed using GraphPad Prism 5.0 (GraphPad Software, Inc.). Statistical comparisons were made between drug-treated groups and vehicle control animals. Data from the open field test were analyzed by non-parametric Mann-Whitney multiple comparison test, whereas the remaining data were analyzed by one-way ANOVA or two-way ANOVA followed by Tukey's multiple range test. $\mathrm{P}<0.05$ was considered to indicate a statistically significant difference. 

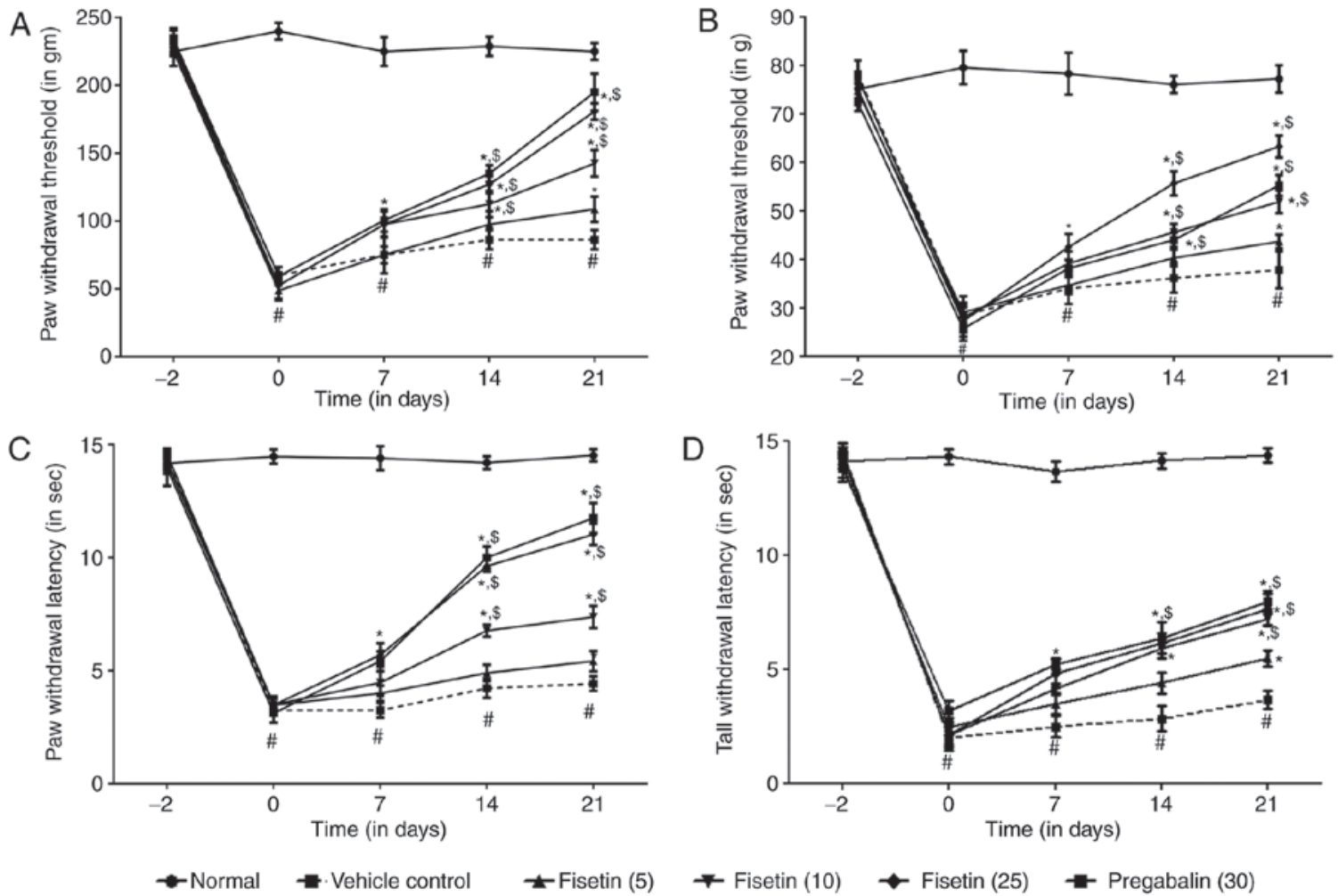

Figure 1. Effect of fisetin on reserpine-induced alterations in (A) mechanical hyperalgesia in the paw pressure test, (B) mechanical allodynia in the von Frey hair test, (C) thermal allodynia in the Hargreaves test, and (D) thermal hyperalgesia in the tail flick test in reserpine-induced fibromyalgia rats. Data are expressed as the mean \pm standard error of the mean $(n=4)$ and were analyzed by two-way ANOVA followed by Tukey's multiple range test. * $<<0.05$ vs. vehicle control group, ${ }^{\#} \mathrm{P}<0.05$ vs. normal animals and ${ }^{\$} \mathrm{P}<0.05 \mathrm{vs} .30 \mathrm{mg} / \mathrm{kg}$ pregabalin or 5, $10 \mathrm{and} 25 \mathrm{mg} / \mathrm{kg}$ fisetin. Fisetin (5), $5 \mathrm{mg} / \mathrm{kg}$ fisetin for $21 \mathrm{days}$; fisetin (10), $10 \mathrm{mg} / \mathrm{kg}$ fisetin for 21 days; fisetin (25), $25 \mathrm{mg} / \mathrm{kg}$ fisetin for 21 days; pregabalin (30), $30 \mathrm{mg} / \mathrm{kg}$ pregabalin for $21 \mathrm{days}$.

\section{Results}

Effect of fisetin on reserpine-induced alterations in mechanical hyperalgesia and allodynia, thermal hyperalgesia and allodynia, and duration of immobility in rats. No significant differences were observed in mechanical hyperalgesia and allodynia, thermal hyperalgesia and allodynia or duration of immobility in normal and vehicle control rats before the administration of reserpine. Subcutaneous administration of reserpine resulted in significantly increased $(\mathrm{P}<0.05)$ mechanical hyperalgesia, mechanical allodynia and thermal hyperalgesia and allodynia, and it significantly increased $(\mathrm{P}<0.05)$ the duration of immobility in the FST and TST in vehicle control rats compared with normal rats. Administration of fisetin $(10$ and $25 \mathrm{mg} / \mathrm{kg})$ significantly attenuated $(\mathrm{P}<0.05)$ reserpine-induced alterations in mechanical hyperalgesia and allodynia, thermal hyperalgesia and allodynia, and the duration of immobility compared with vehicle control rats. Pregabalin $(30 \mathrm{mg} / \mathrm{kg})$ treatment also significantly attenuated $(\mathrm{P}<0.05)$ reserpine-induced alterations in mechanical hyperalgesia, mechanical allodynia, and thermal hyperalgesia and allodynia, and significantly decreased $(\mathrm{P}<0.05)$ the duration of immobility in the FST and TST compared with vehicle control rats. However, pregabalin $(30 \mathrm{mg} / \mathrm{kg})$ treatment showed a more significant $(\mathrm{P}<0.05)$ attenuation in reserpine-induced alterations in mechanical hyperalgesia and allodynia, thermal hyperalgesia and allodynia, and duration of immobility compared with fisetin treatment (Figs. 1 and 2).
Effect of fisetin on reserpine-induced alterations in open field test and rotarod test in rats. The activity at center, ambulation, total locomotion, rearing, grooming, number of fecal pellets and time spent on rotarod decreased significantly $(\mathrm{P}<0.05)$ in vehicle control rats following subcutaneous administration of reserpine compared with normal rats. However, administration of fisetin (10 and $25 \mathrm{mg} / \mathrm{kg}$ ) significantly relieved these depressive symptoms, as reflected by significantly increased $(\mathrm{P}<0.05)$ total locomotion, rearing, grooming and number of fecal pellets as well as time spent on the rotarod, which reflects motor incoordination, compared with vehicle control rats. Pregabalin $(30 \mathrm{mg} / \mathrm{kg})$ treatment also significantly increased $(\mathrm{P}<0.05)$ the reserpine-induced decrease in activity at center, ambulation, total locomotion, rearing, grooming, number of fecal pellets and time spent on rotarod when compared with vehicle control rats. However, these reserpine-induced depressive symptoms and motor incoordination were more significantly relieved $(\mathrm{P}<0.05)$ by pregabalin $(30 \mathrm{mg} / \mathrm{kg})$ treatment compared with fisetin treatment (Table I).

Effect of fisetin on reserpine-induced alterations in brain monoamines their metabolites in rats. There was a significant decrease $(\mathrm{P}<0.05)$ in the levels of DA, NA and 5-HT, although the ratios of DOPAC/DA and 5-HIAA/5-HT increased significantly $(\mathrm{P}<0.05)$ in the spinal cord, thalamus and prefrontal cortex in vehicle control rats compared with normal rats. Treatment with fisetin $(10$ and $25 \mathrm{mg} / \mathrm{kg})$ significantly attenuated $(\mathrm{P}<0.05)$ the reserpine-induced decrease in the levels of these biogenic 
Table I. Effect of fisetin on reserpine-induced alterations in the open field test and rotarod test in reserpine-induced fibromyalgia rats.

Open field test

\begin{tabular}{lccccccc}
\cline { 2 - 6 } Treatment & $\begin{array}{c}\text { Activity } \\
\text { at center }\end{array}$ & Ambulation & $\begin{array}{c}\text { Total } \\
\text { locomotion }\end{array}$ & Rearing & Grooming & $\begin{array}{c}\text { Number of } \\
\text { fecal pellets }\end{array}$ & $\begin{array}{c}\text { Time spent (s) in } \\
\text { the rotarod test }\end{array}$ \\
\hline $\mathrm{N}$ & $20.50 \pm 0.52$ & $107.50 \pm 0.52$ & $128.00 \pm 0.52$ & $16.25 \pm 0.52$ & $23.00 \pm 0.52$ & $5.50 \pm 0.52$ & $52.67 \pm 0.99$ \\
$\mathrm{VC}$ & $2.50 \pm 0.55^{\mathrm{b}}$ & $54.25 \pm 0.55^{\mathrm{b}}$ & $56.75 \pm 0.55^{\mathrm{b}}$ & $6.75 \pm 0.55^{\mathrm{b}}$ & $13.25 \pm 0.55^{\mathrm{b}}$ & $1.25 \pm 0.55^{\mathrm{b}}$ & $6.00 \pm 1.37^{\mathrm{b}}$ \\
$\mathrm{F}(5)$ & $4.50 \pm 0.78$ & $59.50 \pm 0.78$ & $64.00 \pm 0.78$ & $7.50 \pm 0.78$ & $17.50 \pm 0.78$ & $2.00 \pm 0.78$ & $13.00 \pm 1.32$ \\
$\mathrm{~F}(10)$ & $12.75 \pm 0.63^{\mathrm{a}, \mathrm{c}}$ & $82.50 \pm 0.63^{\mathrm{a}, \mathrm{c}}$ & $95.25 \pm 0.63^{\mathrm{a}, \mathrm{c}}$ & $12.50 \pm 0.63^{\mathrm{a}, \mathrm{c}}$ & $17.25 \pm 0.63^{\mathrm{a}, \mathrm{c}}$ & $3.00 \pm 0.63^{\mathrm{a}, \mathrm{c}}$ & $25.17 \pm 0.48^{\mathrm{a}, \mathrm{c}}$ \\
$\mathrm{F}(25)$ & $16.25 \pm 0.57^{\mathrm{a}, \mathrm{c}}$ & $97.00 \pm 0.57^{\mathrm{a}, \mathrm{c}}$ & $113.25 \pm 0.57^{\mathrm{a}, \mathrm{c}}$ & $15.00 \pm 0.57^{\mathrm{a}, \mathrm{c}}$ & $20.00 \pm 0.57^{\mathrm{a}, \mathrm{c}}$ & $3.50 \pm 0.57^{\mathrm{a}, \mathrm{c}}$ & $43.67 \pm 1.26^{\mathrm{a}, \mathrm{c}}$ \\
$\mathrm{P}(30)$ & $18.75 \pm 0.28^{\mathrm{a}, \mathrm{c}}$ & $107.50 \pm 0.52^{\mathrm{a}, \mathrm{c}}$ & $123.25 \pm 0.28^{\mathrm{a}, \mathrm{c}}$ & $15.00 \pm 0.28^{\mathrm{a}, \mathrm{c}}$ & $23.00 \pm 0.28^{\mathrm{a}, \mathrm{c}}$ & $5.00 \pm 0.28^{\mathrm{a}, \mathrm{c}}$ & $47.17 \pm 0.70^{\mathrm{a}, \mathrm{c}}$ \\
\hline
\end{tabular}

Data are expressed as mean \pm standard error of the mean $(n=4)$. Data from the open field test were analyzed by non-parametric Mann-Whitney's multiple comparisons test, whereas the data from the rotarod test were analyzed by one-way ANOVA followed by Tukey's multiple range test. ${ }^{\mathrm{a}} \mathrm{P}<0.05$ vs. vehicle control group, ${ }^{\mathrm{b}} \mathrm{P}<0.05 \mathrm{vs}$. normal animals and ${ }^{\mathrm{C}} \mathrm{P}<0.05 \mathrm{vs} .30 \mathrm{mg} / \mathrm{kg}$ pregabalin or 5,10 and $25 \mathrm{mg} / \mathrm{kg}$ fisetin. $\mathrm{N}$, normal rats; VC, vehicle control rats; F (5), $5 \mathrm{mg} / \mathrm{kg}$ fisetin for 21 days; $\mathrm{F}$ (10), $10 \mathrm{mg} / \mathrm{kg}$ fisetin for 21 days; $\mathrm{F}$ (25), $25 \mathrm{mg} / \mathrm{kg}$ fisetin for $21 \mathrm{days}$; $\mathrm{P}(30), 30 \mathrm{mg} / \mathrm{kg}$ pregabalin for 21 days.

A

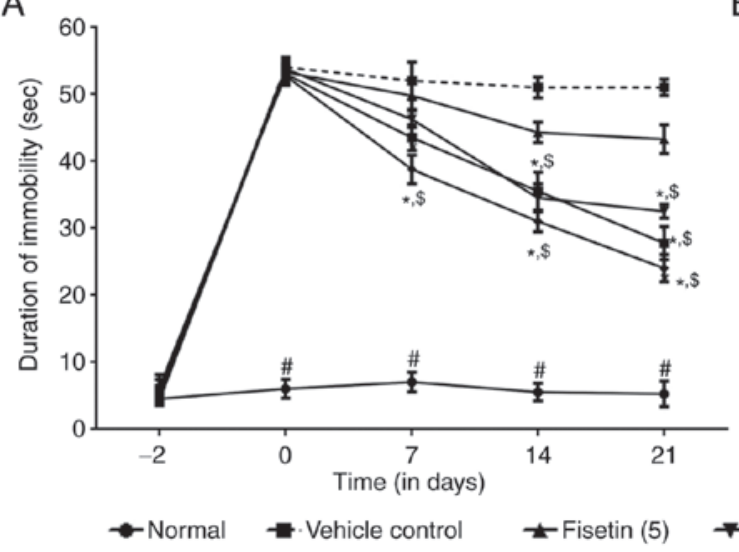

B

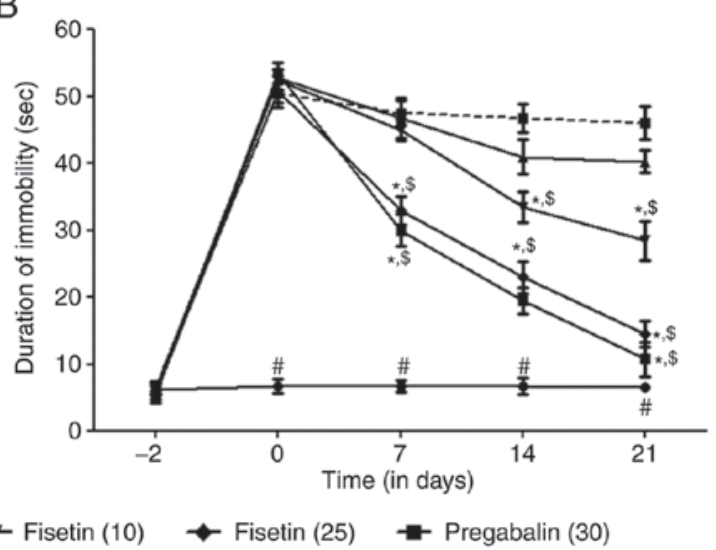

Figure 2. Effect of fisetin on reserpine-induced alterations in the duration of immobility in the (A) forced swim test and (B) tail suspension test in reserpine-induced fibromyalgia rats. Data are expressed as mean \pm standard error of the mean $(n=4)$ and analyzed by two-way ANOVA followed by Tukey's multiple range test. ${ }^{*} \mathrm{P}<0.05$ vs. vehicle control group, ${ }^{\sharp} \mathrm{P}<0.05$ vs. normal animals and ${ }^{\$} \mathrm{P}<0.05 \mathrm{vs} .30 \mathrm{mg} / \mathrm{kg}$ pregabalin or $5,10 \mathrm{and} 25 \mathrm{mg} / \mathrm{kg}$ fisetin. Fisetin $(5), 5 \mathrm{mg} / \mathrm{kg}$ fisetin for 21 days; fisetin (10), $10 \mathrm{mg} / \mathrm{kg}$ fisetin for 21 days; fisetin (25), $25 \mathrm{mg} / \mathrm{kg}$ fisetin for 21 days; pregabalin (30), $30 \mathrm{mg} / \mathrm{kg}$ pregabalin for $21 \mathrm{days}$.

monoamines and increased the ratios with their metabolites in the spinal cord, thalamus and prefrontal cortex compared with vehicle control rats. Pregabalin $(30 \mathrm{mg} / \mathrm{kg})$ treatment also significantly increased $(\mathrm{P}<0.05)$ the levels of $\mathrm{DA}, \mathrm{NA}$ and $5-\mathrm{HT}$ as well as significantly decreasing $(\mathrm{P}<0.05)$ the ratio of DOPAC/DA and 5-HIAA/5-HT in the spinal cord, thalamus and prefrontal cortex compared with vehicle control rats. However, when compared to fisetin treatment, the reserpine-induced decrease in the levels of DA, NA, and 5-HT in the spinal cord, thalamus and prefrontal cortex was more significantly inhibited $(\mathrm{P}<0.05)$ by pregabalin $(30 \mathrm{mg} / \mathrm{kg})$ treatment (Table II).

Effect of fisetin on reserpine-induced alterations in neural $R O S$ in rats. There was significantly increased $(\mathrm{P}<0.05)$ neural ROS reflected by an increase in $\mathrm{H}_{2}$ DCFDA fluorescence after s.c. administration of reserpine in vehicle control rats compared with normal rats. Administration of fisetin (10 and
$25 \mathrm{mg} / \mathrm{kg})$ significantly attenuated $(\mathrm{P}<0.05)$ reserpine-induced increased neural ROS compared with vehicle control rats. Pregabalin $(30 \mathrm{mg} / \mathrm{kg})$ treatment also significantly decreased $(\mathrm{P}<0.05)$ neural ROS when compared with vehicle control rats. However, attenuation of reserpine-induced increased neural ROS was more significant $(\mathrm{P}<0.05)$ following pregabalin $(30$ $\mathrm{mg} / \mathrm{kg}$ ) treatment compared with fisetin treatment (Fig. 3). Effect of fisetin on reserpine-induced alterations in SOD, GSH, MDA and NO in the thalamus of rats. Subcutaneous administration of reserpine resulted in significantly decreased $(\mathrm{P}<0.05)$ levels of SOD and GSH, but significantly increased $(\mathrm{P}<0.05)$ MDA and NO levels in the thalamus in vehicle control rats compared with normal rats. The reserpine-induced decreased thalamic SOD and GSH levels, as well as increased MDA and NO levels, were significantly attenuated $(\mathrm{P}<0.05)$ by fisetin (10 and $25 \mathrm{mg} / \mathrm{kg}$ ) treatment compared with vehicle control rats. Pregabalin $(30 \mathrm{mg} / \mathrm{kg})$ also significantly increased 


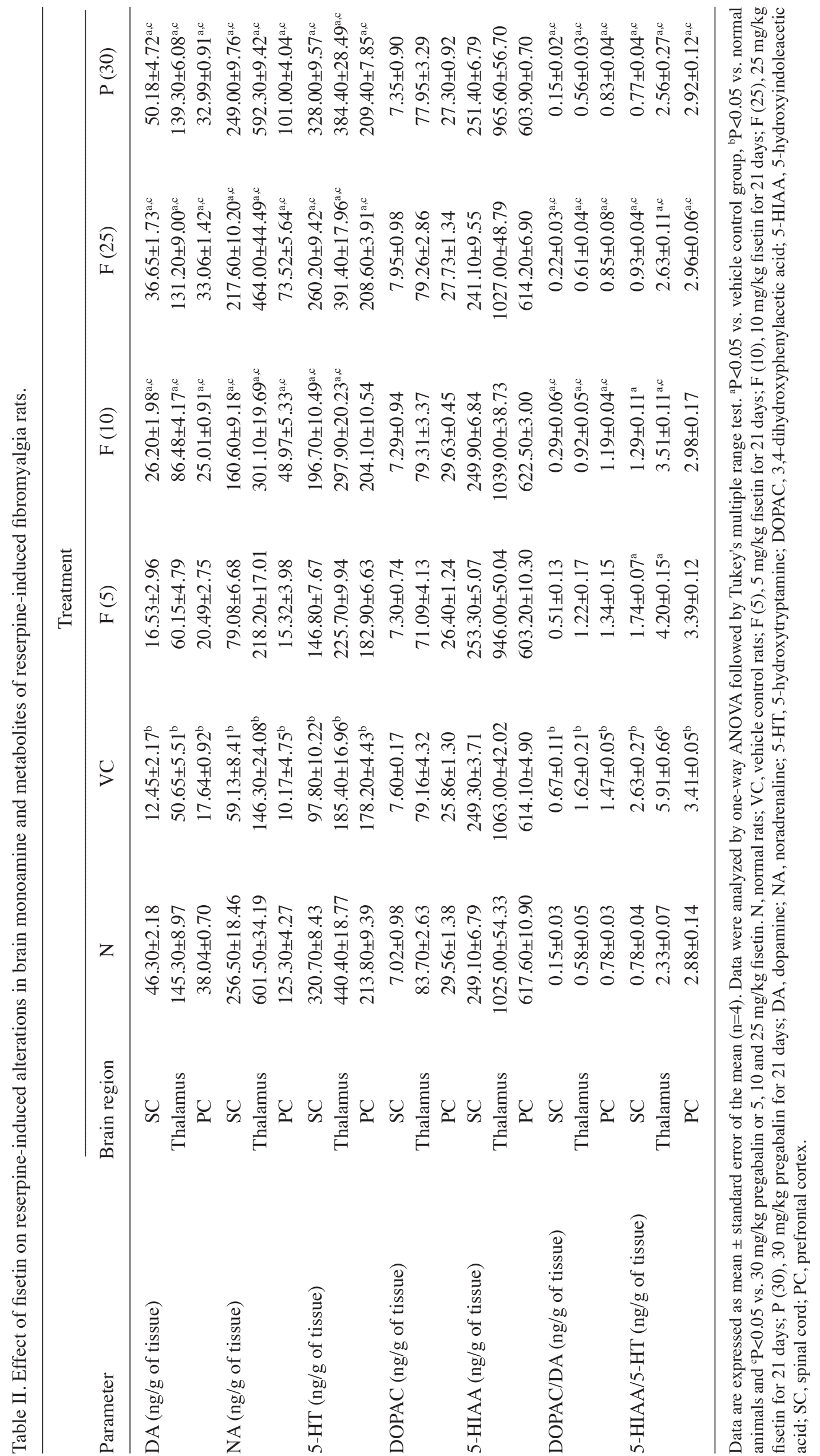


Table III. Effect of fisetin on reserpine-induced alterations in SOD, GSH, MDA, and NO of the thalamus of reserpine-induced fibromyalgia rats.

\begin{tabular}{lcccc}
\hline Treatment & SOD (U/mg of protein $)$ & GSH $(\mu \mathrm{g} / \mathrm{mg}$ of protein $)$ & MDA $(\mathrm{nM} / \mathrm{mg}$ of protein $)$ & NO $(\mu \mathrm{g} / \mathrm{ml})$ \\
\hline $\mathrm{N}$ & $12.93 \pm 1.12$ & $1.34 \pm 0.12$ & $0.42 \pm 0.12$ & $106.60 \pm 9.99$ \\
VC & $3.75 \pm 0.91^{\mathrm{b}}$ & $0.28 \pm 0.06^{\mathrm{b}}$ & $4.21 \pm 0.23^{\mathrm{b}}$ & $280.50 \pm 12.05^{\mathrm{b}}$ \\
$\mathrm{F}(5)$ & $5.22 \pm 0.54$ & $0.30 \pm 0.05$ & $3.45 \pm 0.28$ & $239.80 \pm 14.55$ \\
$\mathrm{~F}(10)$ & $8.87 \pm 0.41^{\mathrm{a}, \mathrm{c}}$ & $0.58 \pm 0.09^{\mathrm{a}, \mathrm{c}}$ & $1.97 \pm 0.18^{\mathrm{a}, \mathrm{c}}$ & $167.60 \pm 19.12^{\mathrm{a}, \mathrm{c}}$ \\
$\mathrm{F}(25)$ & $11.43 \pm 0.53^{\mathrm{a}, \mathrm{c}}$ & $1.25 \pm 0.08^{\mathrm{a}, \mathrm{c}}$ & $1.37 \pm 0.12^{\mathrm{a}, \mathrm{c}}$ & $139.20 \pm 13.20^{\mathrm{a}, \mathrm{c}}$ \\
$\mathrm{P}(30)$ & $11.45 \pm 0.85^{\mathrm{a}, \mathrm{c}}$ & $1.27 \pm 0.11^{\mathrm{a}, \mathrm{c}}$ & $0.47 \pm 0.67^{\mathrm{a}, \mathrm{c}}$ & $128.5 \pm 17.75^{\mathrm{a}, \mathrm{c}}$ \\
\hline
\end{tabular}

Data are expressed as mean \pm standard error of the mean $(n=4)$. Data were analyzed by one-way ANOVA followed by Tukey's multiple range test. ${ }^{\mathrm{a}} \mathrm{P}<0.05$ vs. vehicle control group, ${ }^{\mathrm{b}} \mathrm{P}<0.05$ vs. normal animals and ${ }^{\mathrm{C}} \mathrm{P}<0.05 \mathrm{vs} .30 \mathrm{mg} / \mathrm{kg}$ pregabalin or 5,10 and $25 \mathrm{mg} / \mathrm{kg}$ fisetin. $\mathrm{N}$, normal rats; VC, vehicle control rats; F (5), $5 \mathrm{mg} / \mathrm{kg}$ fisetin for 21 days; F (10), $10 \mathrm{mg} / \mathrm{kg}$ fisetin for 21 days; F (25), $25 \mathrm{mg} / \mathrm{kg}$ fisetin for $21 \mathrm{days}$; $\mathrm{P}$ (30), $30 \mathrm{mg} / \mathrm{kg}$ pregabalin for 21 days; SOD, superoxide dismutase; GSH, reduced glutathione; MDA, malondialdehyde; NO, nitric oxide.

A

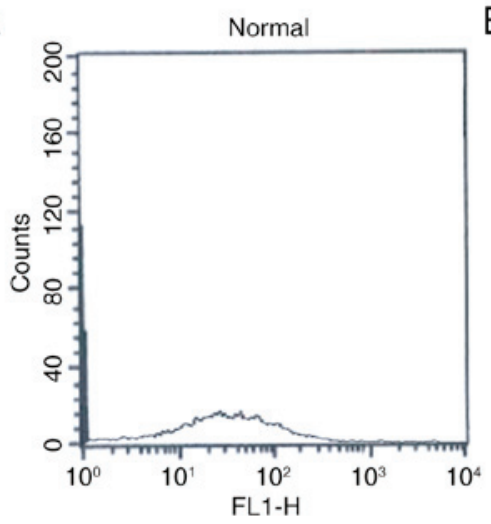

D

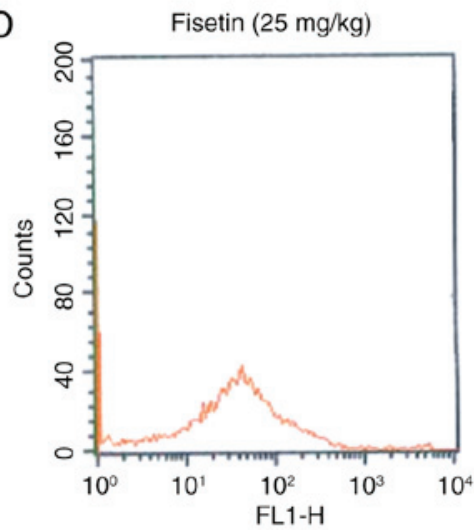

B
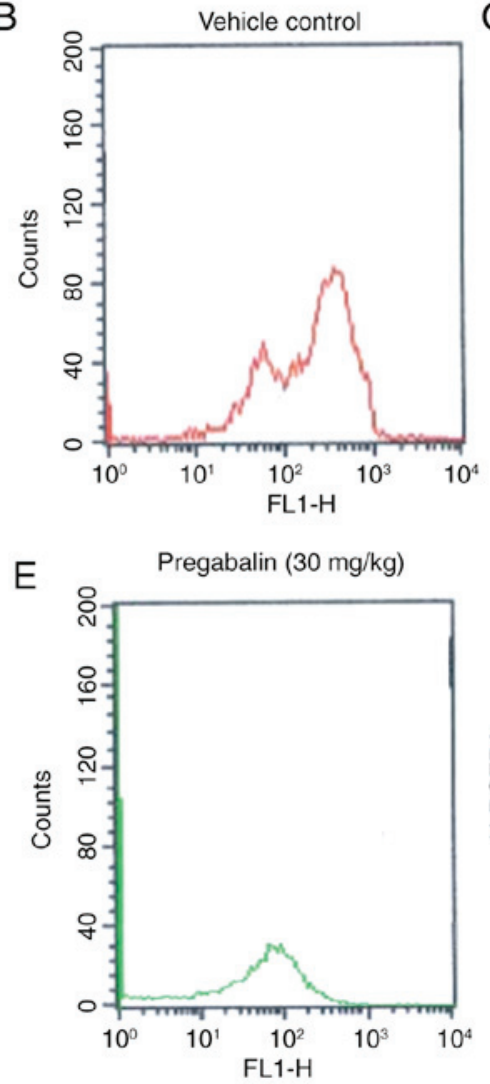

$\mathrm{C}$

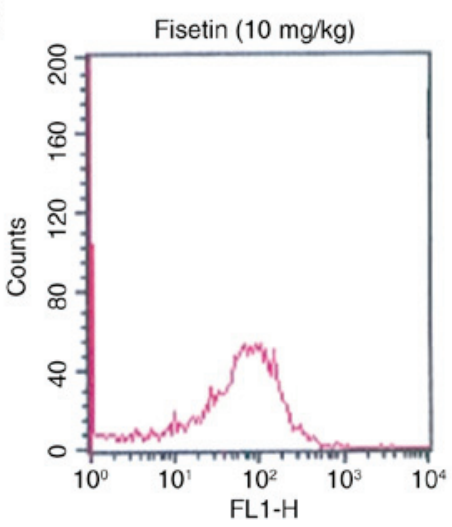

Figure 3. Effect of fisetin on reserpine-induced alterations in neural ROS of RIF rats. Representative image of intracellular ROS production detected by flow cytometry using $\mathrm{H}_{2}$ DCFDA probe in (A) normal, (B) vehicle control, (C) Fisetin (10 mg/kg)-treated, (D) Fisetin (25 mg/kg)-treated and (E) pregabalin $\left(30 \mathrm{mg} / \mathrm{kg}\right.$ )-treateds (E). The quantitative analysis of the effect of fisetin on reserpine-induced alterations in percentage $\mathrm{H}_{2}$ DCFDA fluorescence (F) of RIF rats. Data are expressed as mean \pm standard error of the mean $(n=4)$ and analyzed by one-way ANOVA followed by Tukey's multiple range test. "P $<0.05$ vs. vehicle control group, ${ }^{\prime} \mathrm{P}<0.05$ vs. normal animals and ${ }^{\mathrm{S}} \mathrm{P}<0.05 \mathrm{vs.} 30 \mathrm{mg} / \mathrm{kg}$ pregabalin or $5,10 \mathrm{and} 25 \mathrm{mg} / \mathrm{kg}$ fisetin. ROS, reactive oxygen species; RIF, reserpine-induced fibromyalgia; $\mathrm{H}_{2} \mathrm{DCFDA}$, dichlorodihydrofluorescein diacetate; $\mathrm{F}$ (5), $5 \mathrm{mg} / \mathrm{kg}$ fisetin for 21 days; $\mathrm{F}$ (10), $10 \mathrm{mg} / \mathrm{kg}$ fisetin for $21 \mathrm{days}$; $\mathrm{F}$ (25), $25 \mathrm{mg} / \mathrm{kg}$ fisetin for 21 days; $\mathrm{P}(30), 30 \mathrm{mg} / \mathrm{kg}$ pregabalin for 21 days.

$(\mathrm{P}<0.05)$ levels of SOD and GSH but significantly decreased $(\mathrm{P}<0.05)$ MDA and NO levels in thalamus compared with vehicle control rats. In addition, inhibition of reserpine-induced alterations in thalamic SOD, GSH, MDA and NO levels were more significant $(\mathrm{P}<0.05)$ following pregabalin $(30 \mathrm{mg} / \mathrm{kg})$ treatment compared with fisetin treatment (Table III).
Effect of fisetin on reserpine-induced alterations in 5-HT expression in the thalamus of rats. The number of 5-HT positive neurons was significantly decreased $(\mathrm{P}<0.05)$ following subcutaneous administration of reserpine in vehicle control rats compared with normal rats. However, the reserpine-induced decrease in the number of 5-HT positive neurons was 

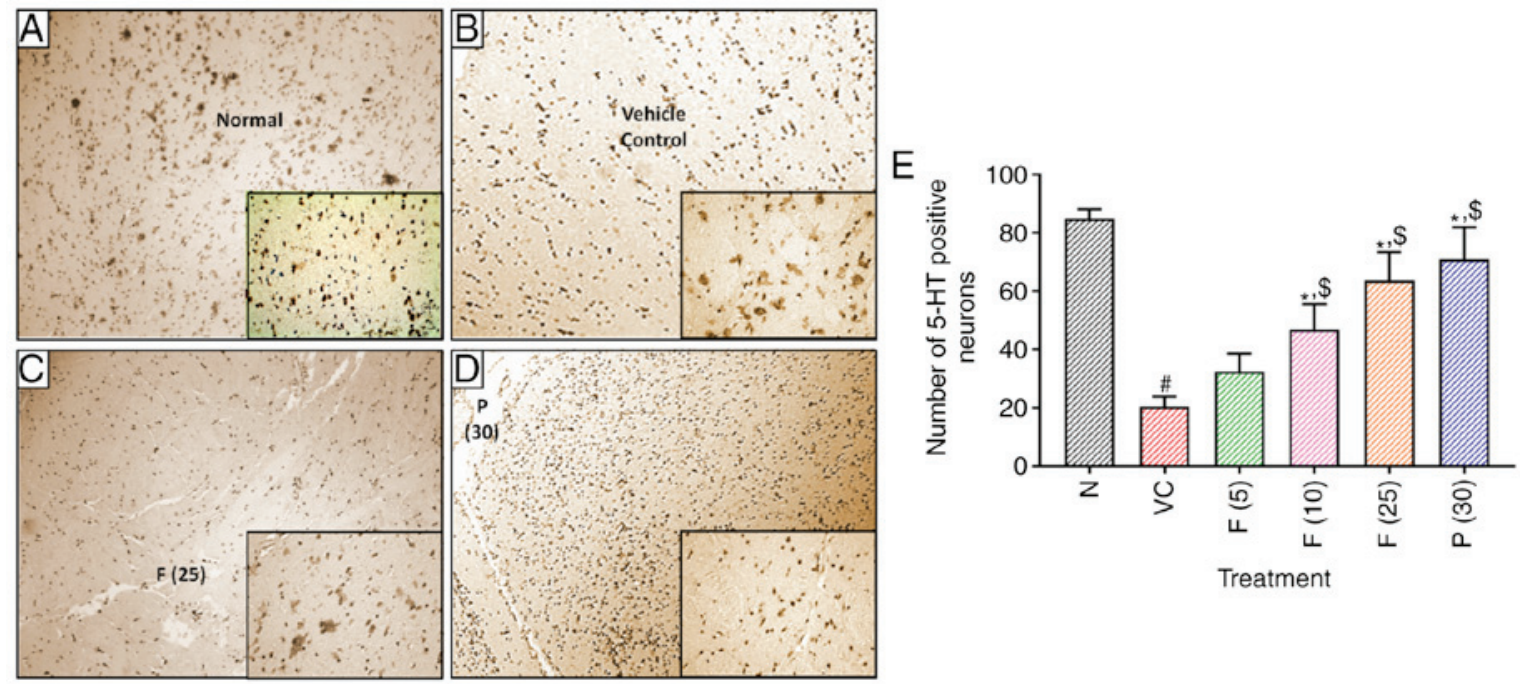

Figure 4. Effect of fisetin on reserpine-induced alterations in 5-HT expression in the brain thalamus of RIF rats. Representative images (at x40 and x100 magnifications) are presented of a section of brain thalamus of (A) normal, (B) vehicle control, (C) fisetin (25 mg/kg)-treated and (D) pregabalin (30 mg/kg)-treated rats. (E) Quantitative analysis of the effect of fisetin on reserpine-induced alterations in 5-HT expression in the brain thalamus of RIF rats. Data are expressed as mean \pm standard error of the mean $(n=4)$ and analyzed by one-way ANOVA followed by Tukey's multiple range test. "P $<0.05$ vs. vehicle control group, ${ }^{\#} \mathrm{P}<0.05$ vs. normal animals and ${ }^{\$} \mathrm{P}<0.05$ vs. $30 \mathrm{mg} / \mathrm{kg}$ pregabalin or 5, 10 and $25 \mathrm{mg} / \mathrm{kg}$ fisetin. RIF, reserpine-induced fibromyalgia; 5-HT, 5-hydroxytryptamine; F (5), $5 \mathrm{mg} / \mathrm{kg}$ fisetin for 21 days; F (10), $10 \mathrm{mg} / \mathrm{kg}$ fisetin for 21 days; F (25), $25 \mathrm{mg} / \mathrm{kg}$ fisetin for $21 \mathrm{days}$; (30), $30 \mathrm{mg} / \mathrm{kg}$ pregabalin for $21 \mathrm{days}$.

significantly increased $(\mathrm{P}<0.05)$ by fisetin $(10$ and $25 \mathrm{mg} / \mathrm{kg})$ compared with vehicle control rats. Pregabalin $(30 \mathrm{mg} / \mathrm{kg})$ also significantly increased $(\mathrm{P}<0.05)$ the number of 5 -HT positive neurons when compared with vehicle control rats. However, the increase in the number of 5-HT positive neurons was more significant $(\mathrm{P}<0.05)$ following pregabalin $(30 \mathrm{mg} / \mathrm{kg})$ treatment as compared with fisetin treatment (Fig. 4).

\section{Discussion}

FM is a complex chronic musculoskeletal disorder characterized by chronic fatigue syndrome, neuropathic pain, allodynia, migraine, mood disorders, depression, sleep disturbances and neurocognitive impairment (13). RIF is highly reproducible and a well-established animal model that induces FM-like symptoms in murine experiments $(22,36)$. Chronic administration of reserpine ( $1 \mathrm{mg} / \mathrm{kg}$ s.c., for 3 consecutive days) causes systemic depletion of biogenic amines (DA, 5-HT and NA), which results in increased nociception and depression in experimental rats (22). In the present study, treatment with fisetin significantly attenuated the reserpine-induced changes in the paw or tail withdrawal thresholds (as evaluated by the von Frey hair test, Randall-Selitto test and Hargreaves test), reserpine-induced depression (reflected by decreased immobility time in the FST and TST), reserpine-induced decreased levels of biogenic amines (5-HT, DA and NE) in the spinal cord, thalamus and prefrontal cortex, and elevated oxido-nitrosative stress and ROS in RIF rats.

It has been documented that reserpine is a potent inhibitor of vesicular monoamine transporter 2 , which interferes in the storage and re-uptake of monoamine in the vesicles $(22,48)$. It further depletes the levels of various monoamines such as 5-HT, DA and NA in the brain nerve terminals, resulting in the induction of depression-like syndrome (45). DA has been suggested to play a vital role in modulation of pain in the CNS and treatment with DA receptor agonists have been shown to ameliorate experimental allodynia and hyperalgesia (7). An animal model of spinal cord injury also exhibited nociceptive hypersensitivity in response to a decrease in the level of DA (49). In addition, the levels of monoamines in the cerebrospinal fluid of patients with FM have been found to decrease significantly (9). Noxious stimulation in the tibialis muscle of patients with FM does not show any significant release of DA in the basal ganglia, indicating the potential role of DA in pain control (7). On the other hand, NE and 5-HT are important endogenous neurotransmitters which play important roles in the descending analgesic pathway from midbrain periaqueductal gray matter to the terminus of the spinal cord (50). Alterations in the levels of NE and 5-HT result in the generation of noxious pain leading to the intensification of the symptoms of central pain in patients with FM $(9,51)$. The results of the present study were all in accordance with the model established by Nagakura (22), wherein reserpine administration altered the levels of biogenic amines (5-HT, NA and DA) as well as their metabolites (5-HIAA and DOPAC) in the CNS $(22,36)$. In the present study, increased DOPAC/DA ratio in the CNS suggested the increased activity of cytoplasmic substrate amine for DA in the presynaptic neuronal ending. Thus, these substrate carriers may be responsible for the elevated levels of DA and 5-HT in the cytoplasm of the presynaptic terminal $(22,36)$. Therefore, increased ratios of DOPAC/DA and 5-HIAA/5-HT were associated with dopaminergic and serotonergic control in the spinal cord, thalamus and prefrontal cortex. A previous study identified that alterations in the levels of these metabolites in the postsynaptic receptors are responsible for heat and cold sensitization (45). It has also been shown that inhibition of the reuptake of these biogenic amines (5-HT, NA and DA) at the synaptic terminal produces antiallodynic and antihyperalgesic effects in FM $(45,52)$. Data from the present study demonstrated that the administration of 
fisetin significantly attenuated the reserpine-induced decrease in the levels of DA, serotonin and NE, as well as increasing the ratios of their metabolites in the spinal cord, thalamus and prefrontal cortex. The result of the present study is in line with the findings of a previous study where fisetin exerts its neuroprotective potential via modulation of these biogenic amines and their metabolites in the CNS (34).

It has been documented that biogenic amines (5-HT, NA and DA) play a vital role in the intrinsic control of central as well as peripheral pain (22). Clinically, brain mapping studies have shown that different regions of the brain are accountable for responses to various mechanical and thermal stimuli against pain $(53,54)$. Alterations in the levels of 5-HT contribute to hyperpolarization or depolarization of primary afferent neurons which causes activation of the analgesic pathway endogenously $(51,55)$, whereas DA levels are associated with trigeminal neuronal sensitization (56). Furthermore, endogenous NA induces peripheral nociceptive sensitivities to a low extent in physiological conditions, whereas it produces pronociceptive effects to a greater extent in neuropathic conditions (57). The primary symptoms of FM are widespread musculoskeletal pain, and this clinical characteristic is closely mimicked by a reserpine-induced model $(22,36)$. Since repeated administration of reserpine is associated with significant alterations in the levels of this biogenic amine (22), it induces alterations in allodynia and hyperalgesia (paw or tail withdrawal threshold). Previous studies implicated an array of therapeutic moieties which exert their potential against the modulation of single biogenic amines that influence either allodynia or hyperalgesia $(53,54)$. Thus, it has been suggested that modulation of multiple biogenic amines is beneficial for the significant amelioration of nociception $(53,54)$. Data from the present study suggested that the administration of fisetin significantly attenuated reserpine-induced allodynia and hyperalgesia by balancing biogenic amines in various regions of CNS. A previous study also suggested the ameliorative potential of fisetin against allodynia and hyperalgesia, exerted via modulation of these biogenic amines, and the results of the present study are in accordance with these findings (58).

Previous studies have shown that depression-like symptoms and cognitive impairment are other troubling symptoms of FM, together with chronic pain $(45,59)$. Inhibition in activity at the DA receptor in the striatal region via a decrease in the concentrations of calcium and sodium channels at the presynaptic ending results in a significant decrease in locomotor activity (60). Thus, DA has been determined to play a vital role during the pathogenesis of depression (61). Along with DA, 5-HT has also been suggested as an important neurotransmitter that is involved in the pathogenesis of major depressive disorders (55). Importantly, it has been reported that repetitive administration of reserpine is associated with depression, as depression is a serious clinical side effect (62). Chronic administration of reserpine induces neurotoxicity via hyperactivity of motor neurons, which is thought to be the underlying mechanism of depression (63). In animals, chronic administration of reserpine also induces depression-like symptoms, and the FST and TST have been widely used to evaluate the potential of various agents against depression $(64,65)$. In the present study, repetitive administration of reserpine increased immobility time in the FST and TST, suggesting that depression is a common comorbidity along with allodynia and hyperalgesia in FM. However, treatment with fisetin significantly decreased immobility time in the FST and TST, suggesting its anti-depressive mechanism via modulation of both the noradrenergic and serotonergic systems. The results of the present study are consistent with the findings of a previous investigation, which showed that fisetin exerts its anti-immobility potential in the FST and TST via endogenous inhibition of 5-HT depletion (34).

A number of studies have suggested that motor symptoms are regulated by brain biogenic amines $(53,64,66)$. Blockage of DA receptors at the presynaptic level results in an imbalance in postural motor control (66). Chronic administration of reserpine induces depletion of DA in nerve terminals via modulation of magnesium- and ATP-dependent mechanisms. Thus, reserpine induces depletion of brain monoamines, which in turn induces the reduction of spontaneous locomotor activity that reflects an impairment in motor function (25). The open field test and rotarod test are the most common and widely used behavioral methods for the assessment of locomotor activity in experimental animals (45). A decrease in rearing behavior and number of square entries in the open field test, and less time spent on the rotarod, indicates a significant decrease in locomotor activity $(38,39)$. In the present study, fisetin treatment significantly ameliorates reserpine-induced decreases in locomotor activity via its inhibitory potential against the deletion of DA. A study carried out by Maher et al (25) also reported the potential of fisetin towards maintaining locomotive activity at normal levels, and the results of the present study are in line with the findings of a previous investigator.

Oxidative stress has been suggested as an important pathophysiological event responsible for the development of various neurological disorders, such as anxiety, depression, epilepsy, Huntington's disease, Parkinson's disease and Alzheimer's disease $(12,13)$. Patients with FM also show decreased plasma antioxidant levels and increased activity of lipid peroxidation (14). Furthermore, mitochondrial dysfunction has also been demonstrated as an important pathway involved in the development of chronic pain syndrome in FM (14). In the neural tissue, reduced GSH is present in abundance, which has been recognized as a cellular nonprotein thiol as it shields neural cells from the damaging effect of free radicals (67). GSH serves as an important antioxidant via its ROS scavenging potential $(14,68)$. It has been reported that reserpine depletes monoamines via autoxidation of DA through inhibition of vesicular monoamine transportation or storage $(11,28,69)$. Furthermore, reserpine also induces oxidative catabolism through monoamine oxidase (69). These vicious cycles are associated with the generation of hydrogen peroxide and quinones in DA neurons, which induce alterations in the redox status of its neural terminals, reflected by decreased concentrations of SOD and GSH (67). A previous study established the link between $\mathrm{NO}$ and musculoskeletal pain in FM (70). NO is a vital molecule involved in neurotransmitter signaling, but its excess production leads to neurotoxicity via DA cell apoptosis (71). In the present study, RIF rats exhibited decreased levels of SOD and GSH, but elevated levels of ROS, MDA and NO. It has been suggested that dietary polyphenols such as fisetin have the ability to penetrate the blood-brain barrier, leading to their elevated levels in the brain after oral administration, which in 
turn modulate the activity of intracellular antioxidants (27). In the present study, oral administration of fisetin significantly attenuates the reserpine-induced elevated ROS and oxidative stress in neural tissue. Similar findings were documented in a previous study, where pretreatment with fisetin attenuated neurotoxicity via the inhibition of oxidative stress (72).

Currently, pregabalin has been approved by the US Food and Drug Administration as a standard treatment for FM and related neuropathic pain (21). A previous study demonstrated that pregabalin inhibited the release of NE and substance $\mathrm{P}$ via binding with the $\alpha-2-\Delta$ subunit of voltage-gated presynaptic calcium channels to exert beneficial effects in FM symptoms (73). However, pregabalin produces only partial relief and does not cure FM (74). In the past few decades, medicines of herbal origin, including Rhizoma drynariae (75) and Baishao zongdai (68), demonstrated significant efficacy in terms of safety in the management of FM. Fisetin, a flavonoid polyphenol phytoconstituent, also showed promising potential for the clinical management of colorectal cancer (76). A few human clinical studies have been performed using fisetin as a dietary supplement for the management of various disorders, including frailty syndrome, mild cognitive impairment, diabetic nephropathy and Gulf War Syndrome (77). Fisetin could be a potential clinical candidate for the management of RIF. Although fisetin showed a beneficial effect against RIF, one limitation of the present study is that the beneficial outcomes have limited scope for extrapolation.

In conclusion, the results of the present study revealed that fisetin ameliorates allodynia, hyperalgesia and depression in RIF. The antinociceptive and anti-depressive effects of fisetin are rendered via modulation of decreased levels of biogenic amines (5-HT, NA and DA), elevated oxido-nitrosative stress and reactive oxygen species in RIF rats.

\section{Acknowledgements}

The authors acknowledge Dr. Shivajirao Kadam, Vice-Chancellor, and Dr Kakasaheb Mahadik, Principal, Poona College of Pharmacy, Bharati Vidyapeeth Deemed University (Pune, India) for providing the necessary facilities to carry out the study.

\section{Funding}

No funding was received.

\section{Availability of data and materials}

The datasets used and/or analyzed during the current study are available from the corresponding author on reasonable request.

\section{Authors' contributions}

XY and ADK conceived and designed the current study. LL, AMK and XY analyzed and interpreted the data. ADK and AMK acquired the data. LL, AMK and SLB drafted the manuscript. SLB revised the manuscript critically for important intellectual content and analyzed the data. All authors provided their approval for the final version of the manuscript to be published.

\section{Ethics approval and consent to participate}

The experimental protocol was approved by the Institutional Animal Ethics Committee (IAEC) of Poona College of Pharmacy (Pune, India) and performed in accordance with the guidelines of Committee for Control and Supervision of Experimentation on Animals, Government of India on animal experimentation.

\section{Patient consent for publication}

Not applicable.

\section{Competing interests}

The authors declare that they have no competing interests.

\section{References}

1. Maletic V and Raison CL: Neurobiology of depression, fibromyalgia and neuropathic pain. Front Biosci (Landmark Ed) 14: 5291-5338, 2009.

2. Staud R and Rodriguez ME: Mechanisms of disease: Pain in fibromyalgia syndrome. Nat Clin Pract Rheumatol 2: 90-98, 2006.

3. Walitt B, Nahin RL, Katz RS, Bergman MJ and Wolfe F: The prevalence and characteristics of fibromyalgia in the 2012 national health interview survey. PLoS One 10: e0138024, 2015.

4. Borchers AT and Gershwin ME: Fibromyalgia: A critical and comprehensive review. Clin Rev Allergy Immunol 49: 100-151, 2015.

5. Arnold LM: Biology and therapy of fibromyalgia. New therapies in fibromyalgia. Arthritis Res Ther 8: 212, 2006.

6. Ghavidel-Parsa B, Bidari A, Amir Maafi A and Ghalebaghi B: the iceberg nature of fibromyalgia burden: The clinical and economic aspects. Korean J Pain 28: 169-176, 2015.

7. Wood PB, Holman AJ and Jones KD: Novel pharmacotherapy for fibromyalgia. Expert Opin Investig Drugs 16: 829-841, 2007.

8. Dadabhoy D, Crofford LJ, Spaeth M, Russell IJ and Clauw DJ: Biology and therapy of fibromyalgia. Evidence-based biomarkers for fibromyalgia syndrome. Arthritis Res Ther 10: 211, 2008.

9. Russell IJ, Vaeroy H, Javors M and Nyberg F: Cerebrospinal fluid biogenic amine metabolites in fibromyalgia/fibrositis syndrome and rheumatoid arthritis. Arthritis Rheum 35: 550-556, 1992.

10. Mense S: Neurobiological concepts of fibromyalgia-the possible role of descending spinal tracts. Scand J Rheumatol Suppl 113: 24-29, 2000.

11. Wasik A, Romanska I and Antkiewicz-Michaluk L: 1-Benzyl-1,2,3,4-tetrahydroisoquinoline, an endogenous parkinsonism-inducing toxin, strongly potentiates MAO-dependent dopamine oxidation and impairs dopamine release: Ex vivo and in vivo neurochemical studies. Neurotox Res 15: 15-23, 2009.

12. Sánchez-DomínguezB,BullónP,Román-MaloL,Marín-AguilarF, Alcocer-Gómez E, Carrión AM, Sánchez-Alcazar JA and Cordero MD: Oxidative stress, mitochondrial dysfunction and, inflammation common events in skin of patients with fibromyalgia. Mitochondrion 21: 69-75, 2015.

13. Bjorklund $G$, Dadar $M$, Chirumbolo $S$ and Aaseth J: Fibromyalgia and nutrition: Therapeutic possibilities? Biomed Pharmacother 103: 531-538, 2018.

14. Cordero MD, de Miguel M, Carmona-López I, Bonal P, Campa F and Moreno-Fernández AM: Oxidative stress and mitochondrial dysfunction in fibromyalgia. Neuro Endocrinol Lett 31: 169-173, 2010.

15. Bateman L, Palmer RH, Trugman JM and Lin Y: Results of switching to milnacipran in fibromyalgia patients with an inadequate response to duloxetine: A phase IV pilot study. J Pain Res 6: 311-318, 2013.

16. Siler AC, Gardner H, Yanit K, Cushman T and McDonagh M: Systematic review of the comparative effectiveness of antiepileptic drugs for fibromyalgia. J Pain 12: 407-415, 2011. 
17. Younger J, Noor N, McCue R and Mackey S: Low-dose naltrexone for the treatment of fibromyalgia: Findings of a small, randomized, double-blind, placebo-controlled, counterbalanced, crossover trial assessing daily pain levels. Arthritis Rheum 65: 529-538, 2013

18. Hadikusumo B and Ng B: Serotonin syndrome induced by duloxetine. Aust N Z J Psychiatry 43: 581-582, 2009.

19. Nüesch E, Häuser W, Bernardy K, Barth J and Jüni P: Comparative efficacy of pharmacological and non-pharmacological interventions in fibromyalgia syndrome: Network meta-analysis. Ann Rheum Dis 72: 955-962, 2013.

20. Hussain SA, Al K II, Jasim NA and Gorial FI: Adjuvant use of melatonin for treatment of fibromyalgia. J Pineal Res 50 267-271, 2011.

21. Gilron I, Tu D, Holden R, Towheed T, Ziegler D, Wang L, Milev R and Gray C: Innovations in the management of musculoskeletal pain with alpha-lipoic acid (IMPALA Trial): Study protocol for a double-blind, randomized, placebo-controlled crossover trial of alpha-lipoic acid for the treatment of fibromyalgia pain. JMIR Res Protoc 6: e41, 2017.

22. Nagakura Y: Recent advancements in animal models of fibromyalgia. Myopain 23: 104-111, 2015.

23. La Torre F and Nicolai AP: Clinical use of micronized purified flavonoid fraction for treatment of symptoms after hemorrhoidectomy: Results of a randomized, controlled, clinical trial. Dis Colon Rectum 47: 704-710, 2004.

24. Fiorani M, Accorsi A and Cantoni O: Human red blood cells as a natural flavonoid reservoir. Free Radic Res 37: 1331-1338, 2003.

25. Maher P, Dargusch R, Bodai L, Gerard PE, Purcell JM and Marsh JL: ERK activation by the polyphenols fisetin and resveratrol provides neuroprotection in multiple models of Huntington's disease. Hum Mol Genet 20: 261-270, 2011

26. Mazzio EA, Harris N and Soliman KF: Food constituents attenuate monoamine oxidase activity and peroxide levels in C6 astrocyte cells. Planta Med 64: 603-606, 1998

27. Maher P: The flavonoid fisetin promotes nerve cell survival from trophic factor withdrawal by enhancement of proteasome activity. Arch Biochem Biophys 476: 139-144, 2008.

28. Maher P: Modulation of multiple pathways involved in the maintenance of neuronal function during aging by fisetin. Genes Nutr 4: 297-307, 2009

29. Maher P, Dargusch R, Ehren JL, Okada S, Sharma K and Schubert D: Fisetin lowers methylglyoxal dependent protein glycation and limits the complications of diabetes. PLoS One 6 : e21226, 2011

30. Kandhare AD, Raygude KS, Ghosh P and Bodhankar SL: The ameliorative effect of fisetin, a bioflavonoid, on ethanol-induced and pylorus ligation-induced gastric ulcer in rats. Inter J Green Pharmacy 5: 236-243, 2011.

31. Raygude KS, Kandhare AD, Ghosh P and Bodhankar SL: Anticonvulsant effect of fisetin by modulation of endogenous biomarkers. Biomed Prev Nutr 2: 215-222, 2012.

32. Zhao L, Kandhare A, Mukherjee A and Bodhankar S: Anti-allergic potential of fisetin in a murine model of OVA-induced allergic rhinitis via inhibition of GATA-3 and Th2 cytokines. Biomedica 34: 88-101, 2018.

33. Ma T, Kandhare AD, Mukherjee-Kandhare AA and Bodhankar SL: Fisetin, a plant flavonoid ameliorates doxorubicin-induced cardiotoxicity in experimental rats: The decisive role of caspase-3, COX-II, cTn-I, iNOs and TNF- $\alpha$. Mol Biol Rep 46: 105-118, 2019.

34. Zhen L, Zhu J, Zhao X, Huang W, An Y, Li S, Du X, Lin M, Wang Q, Xu Y and Pan J: The antidepressant-like effect of fisetin involves the serotonergic and noradrenergic system. Behav Brain Res 228: 359-366, 2012

35. CPCSEA: Committee for the purpose of control and supervision of experiments on animals, 1991

36. Nagakura Y, Oe T, Aoki T and Matsuoka N: Biogenic amine depletion causes chronic muscular pain and tactile allodynia accompanied by depression: A putative animal model of fibromyalgia. Pain 146: 26-33, 2009.

37. Kamble H, Kandhare AD, Bodhankar S, Mohan V and Thakurdesai P: Effect of low molecular weight galactomannans from fenugreek seeds on animal models of diabetes mellitus. Biomed Aging Pathol 3: 145-151, 2013.

38. Kandhare AD, Raygude KS, Ghosh P, Ghule AE and Bodhankar SL: Neuroprotective effect of naringin by modulation of endogenous biomarkers in streptozotocin induced painful diabetic neuropathy. Fitoterapia 83: 650-659, 2012.
39. Kandhare AD, Raygude KS, Ghosh P, Ghule AE and Bodhankar SL: Therapeutic role of curcumin in prevention of biochemical and behavioral aberration induced by alcoholic neuropathy in laboratory animals. Neurosci Lett 511: 18-22, 2012.

40. Adil M, Kandhare AD, Dalvi G, Ghosh P, Venkata S, Raygude KS and Bodhankar SL: Ameliorative effect of berberine against gentamicin-induced nephrotoxicity in rats via attenuation of oxidative stress, inflammation, apoptosis and mitochondrial dysfunction. Ren Fail 38: 996-1006, 2016.

41. Adil M, Kandhare AD, Ghosh P and Bodhankar SL: Sodium arsenite-induced myocardial bruise in rats: Ameliorative effect of naringin via TGF- $\beta / \mathrm{Smad}$ and $\mathrm{Nrf} / \mathrm{HO}$ pathways. Chem Biol Interact 253: 66-77, 2016.

42. Kandhare AD, Alam J, Patil MV, Sinha A and Bodhankar SL: Wound healing potential of naringin ointment formulation via regulating the expression of inflammatory, apoptotic and growth mediators in experimental rats. Pharm Biol 54: 419-432, 2016.

43. Kandhare AD, Raygude KS, Kumar VS, Rajmane AR, Visnagri A, Ghule AE, Ghosh P, Badole SL and Bodhankar SL: Ameliorative effects quercetin against impaired motor nerve function, inflammatory mediators and apoptosis in neonatal streptozotocin-induced diabetic neuropathy in rats. Biomed Aging Pathol 2: 173-186, 2012.

44. Visnagri A, Kandhare AD and Bodhankar SL: Renoprotective effect of berberine via intonation on apoptosis and mitochondrial-dependent pathway in renal ischemia reperfusion-induced mutilation. Ren Fail 37: 482-493, 2015.

45. Blasco-Serra A, Escrihuela-Vidal F, Gonzalez-Soler EM, Martínez-Expósito F, Blasco-Ausina MC, Martínez-Bellver S, Cervera-Ferri A, Teruel-Martí V and Valverde-Navarro AA: Depressive-like symptoms in a reserpine-induced model of fibromyalgia in rats. Physiol Behav 151: 456-462, 2015.

46. Ghule AE, Kandhare AD, Jadhav SS, Zanwar AA and Bodhankar SL: Omega-3-fatty acid adds to the protective effect of flax lignan concentrate in pressure overload-induced myocardial hypertrophy in rats via modulation of oxidative stress and apoptosis. Int Immunopharmacol 28: 751-763, 2015.

47. Zhang L, Wu T, Kandhare A, Mukherjee A, Guo G and Bodhankar S: Elucidation of the molecular mechanism of tempol in pentylenetetrazol-induced epilepsy in mice: Role of gamma-aminobutyric acid, tumor necrosis factor-alpha, interleukin-1\&\#946; and c-Fos. Pharm Mag 14: 520-527, 2018.

48. Antkiewicz-Michaluk L, Wasik A, Możdżeń E, Romańska I and Michaluk J: Antidepressant-like effect of tetrahydroisoquinoline amines in the animal model of depressive disorder induced by repeated administration of a low dose of reserpine: Behavioral and neurochemical studies in the rat. Neurotox Res 26: 85-98, 2014.

49. Horiuchi H, Ogata T, Morino T, Takeba J and Yamamoto H: Serotonergic signaling inhibits hyperalgesia induced by spinal cord damage. Brain Res 963: 312-320, 2003.

50. Willis WD and Westlund KN: Neuroanatomy of the pain system and of the pathways that modulate pain. J Clin Neurophysiol 14: 2-31, 1997.

51. Legangneux E, Mora JJ, Spreux-Varoquaux O, Thorin I, Herrou M, Alvado G and Gomeni C: Cerebrospinal fluid biogenic amine metabolites, plasma-rich platelet serotonin and $\left[{ }^{3} \mathrm{H}\right]$ imipramine reuptake in the primary fibromyalgia syndrome. Rheumatology (Oxford) 40: 290-296, 2001.

52. de Souza AH, da Costa Lopes AM, Castro CJ Jr, Pereira EM Klein CP, da Silva CA Jr, da Silva JF, Ferreira J and Gomez MV: The effects of Ph $\alpha 1 \beta$, a spider toxin, calcium channel blocker, in a mouse fibromyalgia model. Toxicon 81: 37-42, 2014.

53. Borsook D, Moulton EA, Tully S, Schmahmann JD and Becerra L: Human cerebellar responses to brush and heat stimuli in healthy and neuropathic pain subjects. Cerebellum 7: 252-272, 2008.

54. Seifert F, Jungfer I, Schmelz M and Maihofner C: Representation of UV-B-induced thermal and mechanical hyperalgesia in the human brain: A functional MRI study. Hum Brain Mapp 29: $1327-1342,2008$

55. Kaufman J, DeLorenzo C, Choudhury S and Parsey RV: The 5-HT1A receptor in major depressive disorder. Eur Neuropsychopharmacol 26: 397-410, 2016.

56. Charbit AR, Akerman S and Goadsby PJ: Comparison of the effects of central and peripheral dopamine receptor activation on evoked firing in the trigeminocervical complex. J Pharmacol Exp Ther 331: 752-763, 2009. 
57. Pertovaara A: Noradrenergic pain modulation. Prog Neurobiol 80 53-83, 2006

58. Zhao X, Li XL, Liu X, Wang C, Zhou DS, Ma Q, Zhou WH and $\mathrm{Hu} \mathrm{ZY}$ : Antinociceptive effects of fisetin against diabetic neuropathic pain in mice: Engagement of antioxidant mechanisms and spinal GABAA receptors. Pharmacol Res 102: 286-297, 2015.

59. Glass JM: Review of cognitive dysfunction in fibromyalgia: A convergence on working memory and attentional control impairments. Rheum Dis Clin North Am 35: 299-311, 2009.

60. Surmeier DJ, Shen W, Day M, Gertler T, Chan S, Tian X and Plotkin JL: The role of dopamine in modulating the structure and function of striatal circuits. Prog Brain Res 183: 149-167, 2010.

61. Belujon P and Grace AA: Dopamine system dysregulation in major depressive disorders. Int J Neuropsychopharmacol 20 : 1036-1046, 2017

62. Leith NJ and Barrett RJ: Effects of chronic amphetamine or reserpine on self-stimulation responding: Animal model of depression? Psychopharmacology (Berl) 72: 9-15, 1980

63. Franberg O, Marcus MM and Svensson TH: Involvement of 5-HT2A receptor and $\alpha 2$-adrenoceptor blockade in the asenapine-induced elevation of prefrontal cortical monoamine outflow. Synapse 66: 650-660, 2012.

64. Kulkarni SK and Dhir A: On the mechanism of antidepressant-like action of berberine chloride. Eur J Pharmacol 589: 163-172, 2008.

65. Freitas AE, Budni J, Lobato KR, Binfaré RW, Machado DG, Jacinto J, Veronezi PO, Pizzolatti MG and Rodrigues AL: Antidepressant-like action of the ethanolic extract from Tabebuia avellanedae in mice: Evidence for the involvement of the monoaminergic system. Prog Neuropsychopharmacol Biol Psychiatry 34: 335-343, 2010.

66. Johnels B: Locomotor hypokinesia in the reserpine-treated rat: Drug effects from the corpus striatum and nucleus accumbens. Pharmacol Biochem Behav 17: 283-289, 1982.

67. Kandhare AD, Mukherjee AA and Bodhankar SL: Anti-epileptic effect of morin against experimental pentylenetetrazol-induced seizures via modulating brain monoamines and oxidative stress Asian Pac J Trop Biomed 8: 352-359, 2018.

68. Okifuji A, Gao J, Bokat C and Hare BD: Management of fibromyalgia syndrome in 2016. Pain Manag 6: 383-400, 2016.
69. Cordero MD, Alcocer-Gómez E, Cano-Garcia FJ, De Miguel M, Carrión AM, Navas P and Sánchez Alcázar JA: Clinical symptoms in fibromyalgia are better associated to lipid peroxidation levels in blood mononuclear cells rather than in plasma. PLoS One 6: e26915, 2011.

70. Bilska A, Dubiel M, Sokolowska-Jezewicz M, Lorenc-Koci E and Włodek L: Alpha-lipoic acid differently affects the reserpine-induced oxidative stress in the striatum and prefrontal cortex of rat brain. Neuroscience 146: 1758-1771, 2007.

71. Cui J, Wang G, Kandhare AD, Mukherjee-Kandhare AA and Bodhankar SL: Neuroprotective effect of naringin, a flavone glycoside in quinolinic acid-induced neurotoxicity: Possible role of PPAR- $\gamma$, Bax/Bcl-2, and caspase-3. Food Chem Toxicol 121: 95-108, 2018.

72. Rajendran $\mathbf{M}$ and Ramachandran R: Fisetin protects against rotenone-induced neurotoxicity through signaling pathway. Front Biosci (Elite Ed) 11: 20-28, 2019.

73. Boomershine CS: Pregabalin for the management of fibromyalgia syndrome. J Pain Res 3: 81-88, 2010.

74. Kim L, Lipton S and Deodhar A: Pregabalin for fibromyalgia: Some relief but no cure. Cleve Clin J Med 76: 255-261, 2009.

75. Gao GM, Jiang L, Liu SY, Zheng ZH and Liu ZS: A randomized and controlled study of clinical efficacy for total flavone of Rhizoma Drynariae on fibromyalgia syndrome. Chin J New Drug Clin Remedies 26: 837-840, 2007.

76. Farsad-Naeimi A, Alizadeh M, Esfahani A and Darvish Aminabad E: Effect of fisetin supplementation on inflammatory factors and matrix metalloproteinase enzymes in colorectal cancer patients. Food Funct 9: 2025-2031, 2018.

77. Mehta P, Pawar A, Mahadik K and Bothiraja C: Emerging novel drug delivery strategies for bioactive flavonol fisetin in biomedicine. Biomed Pharmacother 106: 1282-1291, 2018.

(i) $\ominus$ This work is licensed under a Creative Commons Attribution-NonCommercial-NoDerivatives 4.0 International (CC BY-NC-ND 4.0) License. 